\title{
Tumores malignos de pálpebra
}

\author{
Malignant eyelid tumors
}

\author{
Luis Henrique Schneider Soares ${ }^{1}$ \\ Cecília Vasconcellos Bello² \\ Andrea Kaercher Loureiro Bing Reis ${ }^{3}$ \\ Ricardo Rodrigues Nunes ${ }^{4}$ \\ Eduardo Marques Mason" 5
}

Hospital Banco de Olhos de Porto Alegre (RS) - Brasil. ${ }^{1}$ Fellowship em Retina e Vítreo no Doheny Eye Institute e USC (University of Southern California) - Los Angeles - California.

${ }^{2}$ Residência em Oftalmologia no Hospital Banco de Olhos de Porto Alegre.

3 Ex-estagiária do Departamento de Plástica Ocular e Órbita do Massachusetts Eye and Ear Infirmary (MEEI) - Boston.

${ }^{4}$ Fellowship em Retina e Vítreo no Doheny Eye Institute e USC (University of Southern California) - Los Angeles - California.

${ }_{5}^{5}$ Chefe do Departamento de Plástica Ocular do Hospital Banco de Olhos de Porto Alegre.

Endereço para correspondência: Luis Henrique Schneider Soares. R. Damazio Trindade, 379 - São Gabriel (RS) CEP 97300-000. E-mail: henriqueschneider (a)hotmail.com

Nota Editorial: Pela análise deste trabalho e por sua anuência sobre a divulgação desta nota, agradecemos a Dra. Lucia Miriam D. Lucci.

\section{RESUMO}

Objetivos: Estudar a incidência de tumores malignos de pálpebra no Hospital Banco de Olhos de Porto Alegre. Métodos: Estudo retrospectivo dos casos de tumores malignos de pálpebra no período de 1985 a 1997, que tiveram diagnóstico confirmado por exame anátomopatológico. Resultados: Foram encontradas 54 neoplasias malignas, sendo $75,92 \%$ carcinoma basocelular, $12,96 \%$ carcinoma espinocelular, $7,40 \%$ melanoma e $1,85 \%$ lentigo maligna. A maioria dos pacientes apresentava mais de 40 anos e não houve prevalência de sexo. Conclusões: $O$ tumor de pálpebra mais freqüente em nosso meio foi o carcinoma basocelular, seguido do carcinoma espinocelular. O melanoma foi o terceiro em freqüência mais encontrado em nossa pesquisa.

Descritores: Carcinoma basocelular; Neoplasias palpebrais; Carcinoma de células escamosas; Tumores; Incidência

\section{INTRODUÇÃOO}

As lesões palpebrais são responsáveis por uma porção importante da prática clínica da oftalmologia.

Apesar de bastante aparentes, o que facilita sua detecção e diagnóstico, ainda pouco se sabe sobre a freqüência destes tumores palpebrais, principalmente em nosso meio. Devido à importância do diagnóstico precoce tanto para menor remoção tecidual como para reconstrução palpebral mais facilitada temos como objetivo deste estudo:

- Conhecer a freqüência e a localização dos tumores palpebrais malignos em nosso meio;

- Conhecer a prevalência em relação ao sexo e a idade dos portadores de tumores malignos de pálpebra.

\section{MÉTODOS}

Foi realizado um estudo de todos os casos de tumores malignos de pálpebra operados no Hospital Banco de Olhos de Porto Alegre no período de 1985 a 1997.

Foram consultados arquivos clínicos e foram incluídos neste estudo todos os casos de tumores malignos de pálpebra que tiveram diagnóstico confirmado por exame anátomo-patológico.

Foram analisadas a freqüência e a localização dos tumores, além da idade e sexo dos pacientes acometidos. 


\section{RESULTADOS}

Foram encontrados 54 tumores palpebrais malignos, sendo $41(75,92 \%)$ carcinomas basocelulares (Ca baso), 7 $(12,96 \%)$ carcinomas espinocelulares (Ca espino), 4 (7,40\%) melanomas (Melanoma), 1 (1,85\%) carcinoma indiferenciado (Ca indif), 1(1,85\%) lentigo maligna (Lentigo) (Tabela 1).

O Ca baso (Gráfico) ocorreu mais em indivíduos na faixa etária dos 70 anos, porém também ocorreu em indivíduos na quarta década de vida. Quanto à prevalência de sexo, ocorreu mais em indivíduos do sexo feminino (Tabela 1). Acometeu mais freqüentemente a pálpebra inferior e a porção interna da pálpebra (Tabela 2 ).

As margens cirúrgicas estavam livres em todos os tumores, evidenciado pelo exame anatomo-patológico, não havendo recidiva no período de 2 anos em que foi feito acompanhamento clínico.

O Ca espino foi o segundo tumor maligno mais freqüente na pálpebra. Ocorreu em indivíduos com média de idade de 60 anos. Houve predileção pelo sexo masculino $(71,42 \%)$ (Tabela 1).

Nos 7 pacientes com Ca espino, 4 ocorreram na pálpebra inferior $(57,14 \%), 2$ acometeram pálpebras superior e inferior $(28,57 \%)$, e 1 apenas acometeu pálpebra superior (14,28\%), não havendo recidiva no período de 2 anos em que foi feito acompanhamento clínico.

O terceiro tipo de tumor palpebral mais freqüente foi o Melanoma, afetando preferentemente idosos, apesar de um caso ter acometido um indivíduo de 35 anos. Houve preferên-

\begin{tabular}{|c|c|c|c|}
\hline \multirow[t]{2}{*}{ Diagnóstico } & \multirow[t]{2}{*}{ Freqüência } & \multicolumn{2}{|c|}{ Sexo } \\
\hline & & Masc. & Fem. \\
\hline CBC & 41 (75,92\%) & 18 & 23 \\
\hline CEC & 7 (12,96\%) & 5 & 2 \\
\hline M & $4(7,40 \%)$ & 1 & 3 \\
\hline $\mathrm{Cl}$ & $1(1,85 \%)$ & 1 & - \\
\hline $\mathrm{L}$ & $1(1,85 \%)$ & 1 & - \\
\hline Total & 54 (100\%) & 26 & 28 \\
\hline
\end{tabular}

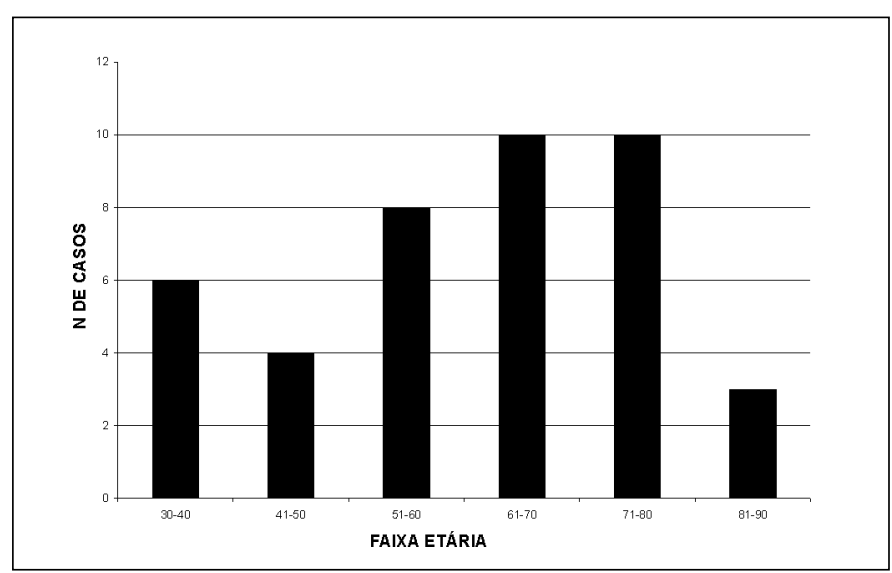

Gráfico - Carcinoma basocelular

cia pelo sexo feminino $(51,85 \%)$ (Tabela 1$)$. Com relação à localização da lesão tumoral, observamos que $100 \%$ das lesões acometeram pálpebra inferior).

$\mathrm{O} \mathrm{Ca}$ indiferenciado ocorreu em um paciente do sexo masculino (Tabela 1) e acometeu pálpebra superior (Tabela 2).

Um paciente de 68 anos, sexo feminino (Tabela 1), apresentou lentigo maligna, que acometeu canto interno (Tabela 2).

\section{DISCUSSÃO}

Lesões cancerosas ocorrem com maior freqüência na pele do que em qualquer outra parte do corpo, estando em parte relacionadas à exposição solar ou a outras radiações eletromagnéticas e também ao contato com carcinógenos químicos, além da predisposição genética. Em países tropicais como o Brasil há uma incidência elevada de lesões de pele por exposição solar ${ }^{(1)}$.

O Ca baso é o tumor de pele mais comum, correspondendo a $90 \%$ dos tumores malignos de pálpebra. Em nossa casuística, o Ca baso foi responsável por $72,34 \%$ das lesões malignas das pálpebras. Em outros estudos, a incidência deste tumor na pálpebra varia de $77,53 \% \%^{(1)}$ a $90 \%{ }^{(2)}$.

Em nosso estudo os indivíduos com $\mathrm{Ca}$ baso apresentavam mais de 40 anos, predominando em indivíduos maiores de 60 anos, porém 6 deles apresentavam-se na quarta década de vida. O Ca baso é mais freqüente após os 60 anos e entre 409

Tabela 2. Distribuição das neoplasias malignas das pálpebras do Hospital Banco de Olhos de Porto Alegre durante o período de 1985 a 1997, por localização da lesão

\begin{tabular}{|c|c|c|c|c|c|c|c|}
\hline & Basocelular & Espinocelular & Melanoma & CA Indif. & Lentigo & Total & $\%$ \\
\hline Pálp. Superior & 5 & 1 & - & 1 & - & 7 & 15,55 \\
\hline Pálp. Inferior & 30 & 4 & 4 & - & - & 38 & 84,44 \\
\hline Toda Pálpebra & 6 & 2 & 2 & - & - & 10 & 20,75 \\
\hline 1/3 externo & 6 & - & - & - & - & 6 & 11,32 \\
\hline Canto Interno & 15 & 3 & 1 & - & 1 & 20 & 37,73 \\
\hline 1/3 Médio & 14 & 1 & 1 & - & - & 16 & 30,18 \\
\hline Sem Informação & - & 1 & - & - & - & 1 & 1,88 \\
\hline
\end{tabular}


Ca baso de pálpebra da Universidade de Iowa, apenas 3,2\% ocorreram entre indivíduos de 21 a 35 anos $^{(3)}$. Predominou em indivíduos do sexo feminino ${ }^{(3)}$, enquanto a literatura aponta um predomínio em indivíduos masculinos ${ }^{(4)}$.

A grande maioria dos Ca baso ocorreu na pálpebra inferior e no canto interno, fato concorde com outros relatos ${ }^{(2,5-6)}$ provavelmente pela maior exposição solar.

Quando não removido por completo, o Ca baso pode recorrer no local, porém metástases ocorrem em $0,1 \%$ dos ca$\operatorname{sos}^{(7)}$. Estes tumores podem erosar ossos periorbitais, invadir o globo e mesmo o cérebro. Em nosso estudo não houve casos de recorrência, invasão profunda, ou metástase tumoral.

O Ca espino em nossa série correspondeu a $12,76 \%$ dos tumores malignos das pálpebras, enquanto na literatura existem relatos de $7 \%^{(8)}$ a $18 \%{ }^{(6)}$.

Segundo descrição realizada na literatura ${ }^{(9)}$ o Ca espino ocorre geralmente em idosos, o que corresponde aos achados deste estudo em que a idade dos pacientes que apresentaram Ca espino variou de 53 a 80 anos.

Conforme constatado por Burnier Jr. et al. ${ }^{(4)} \mathrm{em} 1985$ houve uma grande preferência pelo sexo masculino, já que dos 6 pacientes com Ca espino, 5 eram do sexo masculino.

Nosso estudo contrasta com a literatura em relação à localização do tumor - $83,3 \%$ em pálpebra inferior ou superior e inferior, enquanto segundo outros autores, este tumor ocorre mais na pálpebra superior ${ }^{(5)}$.

O Melanoma maligno na literatura representa lesão neoplásica rara da pálpebra, representando apenas $1 \%$ dos tumores malignos palpebrais ${ }^{(10)}$. Porém, no nosso estudo, encontramos $7,40 \%$ de incidência.

Esta neoplasia é importante por ser um dos cânceres de pele mais agressivos. Dois terços das mortes devido a câncer de pele são secundárias a melanoma maligno.

Houve maior incidência em mulheres, sendo 3 casos em mulheres e $1 \mathrm{em}$ homem. Todos os casos ocorreram na pálpebra inferior, sendo que 2 acometeram toda a pálpebra.

A idade variou de 35 a 82 anos, sendo que dos quatro pacientes acometidos 3 tinham mais de 50 anos. Um caso foi originado em nevo prévio.

O tumor de pálpebra mais freqüente em nosso meio foi o Ca baso $(75,92 \%)$ que teve maior incidência em indivíduos maiores de 40 anos, sexo feminino, mais na pálpebra inferior, porção interna e média.

O Ca espino ocorreu em 12,96\% dos casos, em indivíduos com mais de 53 anos e do sexo masculino. Ocorreu mais freqüentemente em pálpebra inferior.

O Melanoma foi encontrado em 7,40\% dos casos, mais em idosos, sexo feminino e todas as lesões acometeram pálpebra inferior.

\section{ABSTRACT}

Purposes: To study the incidence of eyelid malignant tumors in the Banco de Olhos Hospital of Porto Alegre from 1985 to 1997. Methods: We retrospectivelly analyzed clinical archives and in this study all cases of malignant eyelid tumors with histopathologic examination were included. Results: We found 54 eyelid tumors: $75.92 \%$ basal cell, $12.96 \%$ squamous cell, $7.40 \%$ melanoma, $1.85 \%$ undifferentiated carcinoma and $1.85 \%$ lentigo maligna. The majority of the patients was over 40 years old, $50 \%$ were male and $50 \%$ female. The diagnosis was confirmed in all cases through histopathologic examination. Conclusions: Basal cell carcinoma was the most frequent eyelid malignancy followed by squamous cell carcinoma. Melanoma was the third most frequently found tumor in our study.

Keywords: Carcinoma, basal cell; Eyelid neoplasms; Carcinoma, squamous cell; Tumor; Incidence

\section{REFERÊNCIAS}

1. Schellini AS, Costa JP, Cardilo JA, Paro PT, Marques MEA, Silva MRBM. Neoplasias malignas das pálpebras na Faculdade de Medicina de Botucatu. Rev Bras Oftalmol 1990;49:47-53.

2. Francis IC, Benecke OS, Kappagoda MB. A ten-year hospital survey of eyelid cancer. Aust J Ophthalmol 1984;12:121-7.

3. Nerad JA, Whitaker DC. Periocular basal cell carcinoma in adults 35 years of age and younger. Am J Ophthalmol 1988;106:723-9.

4. Burnier Jr M, Belfort Jr R, Rigueiro MP, Montezzo LC, Chiferi Jr V. Neoplasias malignas da pálpebra. Arch Chil Oftalmol 1985;42:145-53.

5. Halnan KE, Britten MJ. Late functional and cosmetic results of treatment of eyelid tumours. Br J Ophthalmol 1968;52:43-53.

6. Apple DJ, Rabb MF. Conjuntiva and eyelids. In: Apple DJ Ocular pathology $3^{\text {rd }}$ ed St Louis: Mosby; 1985. p. 465-89.

7. Eshler Z, Leviatan A, Peled I, Wexler M. Spinal metastases of basal cell carcinoma. J Surg Oncol 1984;25:28-33.

8. Aurora AL, Blodi FC. Lesions of the eyelids: a clinicopathological study. Surv Ophthalmol 1970;15:95-104.

9. Welch RB, Duke JR. Lesions of the lids: a statistical note. Am J Ophthalmol 1958;45:415-6.

10. Leventhal HH, Messer RJ. Malignant tumors of the eyelid. Am J Surg 1972;124:522-6.

\title{
Novidades na Internet!!!
}

\author{
Agora no site CBO você tem disponível todas as informações na íntegra dos \\ Arquivos Brasileiros de Oftalmologia \\ http://www.cbo.com.br/abo
}

